\title{
The Impact of Value Management Implementation in Malaysia
}

\author{
Aini Jaapar \\ Department of Quantity Surveying, Faculty of Architecture, Planning \& Surveying, \\ Universiti Teknologi MARA \\ 40450 Shah Alam, Selangor, Malaysia \\ Tel: 60-3-5522-5341 E-mail: ainijaapar@salam.uitm.edu.my \\ Intan Rohani Endut (Corresponding author) \\ Department of Construction Engineering \& Project Management \\ Faculty of Civil Engineering \\ 40450 Shah Alam, Selangor, Malaysia \\ Tel: 60-3-5543-5262Ｅ-mail: intan@salam.uitm.edu.my \\ Nor Azmi Ahmad Bari \\ Department of Quantity Surveying, Faculty of Architecture, Planning \& Surveying, \\ Universiti Teknologi MARA \\ 40450 Shah Alam, Selangor, Malaysia
}

Tel: 60-3-5544-4360 E-mail: noraz103@yahoo.com

Roshana Takim

Department of Construction Management, Faculty of Architecture, Planning \& Surveying

Universiti Teknologi MARA

40450 Shah Alam, Selangor, Malaysia

Tel: 60-3-5544-4202 E-mail: rtakim59@yahoo.co.uk

\begin{abstract}
This paper reports on the findings of a study on value management (VM) applications in the Malaysian construction industry. A questionnaire survey of 7 pages was sent to 5581 numbers of registered developers, architects, engineers, quantity surveyors and project managers to seek their experience on VM applications. A return rate of 7.5 per cent or 411 numbers of respondents were received.

During the process of investigation on the evolution in Malaysia, it was discovered that the global evolution of VM did influence the Malaysian construction industry as majority of the public universities had ensured that VM methodology knowledge has been integrated into their syllabuses, thus the future construction industry practitioner has had the basic knowledge on VM methodology provided which should have equipped them for producing a better functionally, and better value for money construction projects.
\end{abstract}

Keywords: Value Management, Development, Questionnaire, Malaysia construction industry

\section{Introduction}

VM is 'a multi-disciplinary, team orientated, structured, analytical process and systematic analysis of function which seeks best value via the design and construction process to meet the client's perceived needs'(Jaapar, 2006; Jaapar \& Torrance, 2005; Jaapar \& Torrance, 2007), a proactive, creative, problem-solving service, using a multi-disciplinary team oriented approach to make explicit the client's value system, at targeted stages through the development of a project or the life of a facility" (Kelly \& Male, 1993; Norton \& McElligott, 1995), a means of group decision support 
(Green, 1999), the most promising method in co-ordinating professionals from different disciplines (Shen, 1995) as well as a method to help the clients better achieve their goals (Connaughton \& Green, 1996; Male, Kelly, Fernie, Gronqvist, \& Bowles, 1998). The VM procedure also encourages the development of a value culture within the organisation which eases the path to accomplishing desirable change. Thus, it can be summarised as a goal-setting process that aims to satisfy the client's project requirements as well as it concentrates on improving the relationship between value and the client.

Internationally, VM is an emerging paradigm that focuses on continuously increasing the value provided to the client and is widely accepted as an important tool in recent management of construction projects (Ellis, Wood, \& Keel, 2005). The construction industry is an important field for VM at the international level (Kelly, Male, \& Graham, 2004) as it is also critical to the success of projects since it provides a basis for improving value for money in construction (Ashworth \& Hogg, 2000). It focuses on value rather than cost and seeks to achieved an optimal balance between time, cost and quality (Kelly et al., 2004) as well as it provides a method of integration in the building process that no other management structure in construction can provide (Kelly \& Male, 1991). It also explores the functional requirements and seeks overall optimisation accordingly(Shen, 1995). Norton and McElligott (1995) strongly advocated that VM should precede Cost Management effort which later was endorsed by (Liu, 2003) who emphasise the importance of VM practice in the construction industry as it has proven that it could provide significant benefits to clients if it is used correctly.

VM was first introduced in Malaysia in 1986 (Jaapar \& Torrance, 2007). Currently there is evidence of some client organisations in Malaysia applying some concepts of VM in their project operations (Abdul Ghani, 2004; BERNAMA, 2002; Che Mat, 1999, 2002; Hussein, 1998; Karim, 1999; Ong \& Yeomans, 2002; Sareh, 2003; Shamsuddin, 2002; Stevens, 1997; Sulaiman, 2000; Tamim, 2002; Yahya, 2003) It is clearly indicated that, in Malaysia, its application is still in its infancy(Abdul Ghani, 2004; Jaapar, 2000; Jaapar \& Torrance, 2005; Ong, 2004a, 2004b) thus, to promote the application of VM in the industry, it is crucial to understand its current state of its application before a system of VM philosophy can be developed to suit the current local scenario.

Unfortunately, VM has not yet become widely practiced in the Malaysia. It was observed that due to some successful applications of VM in the Malaysian construction industry, hence actions should now be taken to exert its full potential to improve value for money for the clients of the industry. It is argued by Che Mat (1999), that the clients' understanding towards the VM concept is important as it is not just merely considering the cost but it considers the relationship between value, function, quality and cost in a wider perspective leading to the fundamental contribution of VM application whereby it eliminated the unnecessary cost which does not contribute to the project's value, system and facilities.

\section{Problem Statement}

The application of the VM concept, is widely accepted internationally especially in the USA, Japan, European countries, and other developing countries such as Australia. In Malaysia, its application is still in its infancy (Jaapar, 2006; Jaapar \& Torrance, 2005; Jaapar \& Torrance, 2007). Thus, to promote the application of VM in the industry, it is crucial to understand its current state of its application in the industry before a system of VM philosophy can be developed to suit the Malaysian construction industry scenario.

\section{Objectives}

This research aimed to achieve two objectives, which were to investigate the current development of VM and its benefits to the Malaysia construction industry and to investigate the current level of VM applications in the Malaysian construction projects.

\section{Significance of the research}

The major theoretical contribution of this research is, it explores the theory of VM and its applications in the Malaysian construction industry and to investigate the current level of applications.

\section{Brief outline of research methodology}

A questionnaire survey was designed, piloted and mailed to ensure information related to the implementation of VM in the Malaysia construction industry could be collected and the respondents' opinions in relation to suggestions, implementation processes and the obstacles with regard to the VM applications. The respondents consisted of the clients and the registered consultants of the construction industry.

\subsection{Population Sample}

A postal questionnaire of 5581 copies, which was developed to collect the level of VM application, was served to the expert clients and the registered consultants who were actively engaged in procuring, designing and construction in the Malaysia construction industry. 
Two groups of respondents were involved in the survey. The respondents consisted of the developers (or the expert clients), and the professional consultants of the industry which were identified as the architects, the engineers, quantity surveyors and the project managers. They were selected to be the respondents due to their important involvement and their impact on the decisions made during the process of the construction project procurement.

The expert clients were very important due to their contribution to the development and growth of Malaysia as a developing country and it is for whom the value is generated. The second group of the respondents was the registered professional consultants of the Malaysian construction industry. These are the people that ensure that project execution proceeded smoothly. According to the WCGPM (2004) project consultants are the persons who provide specialized services based on their special qualifications, education or experience. In this case, the selected consultants were architects, the engineers, the quantity surveyors and the project managers. Only the registered professionals of each discipline were selected to be the respondents of the questionnaire.

The involvement of the clients and the consultants were important to the research since they are the key players who play an active involvement in order to produce the specified buildings and other facilities during the construction process. Therefore, their input must be considered through a thorough understanding of the outcome of the specified construction project. By analysing the information gathered from the various parties from the perspectives of VM, it would be able to enhance the VM services offered by the consultants to improve the clients' requirements in procuring the projects.

\subsection{Sample Surveyed}

According to de Vaus (2001) sample size creates a problem with any type of design. Due to its infancy development of VM (Jaapar \& Torrance, 2005) it was even more important to ensure that as many respondents as possible were being reached so as to ensure that the questionnaire reached the respondents that had experienced with VM application locally. It was stated by Ahmad (2003) that only $2.5 \%$ the receivers of a questionnaire in Malaysia returned the questionnaire received and this low rate is supported by Jaapar, Torrance, \& Yusuf (2004) in which the response rate received was $5 \%$. There were some elements that were considered thoroughly during the process of deciding the sample size of the respondents. If a sample size of 2000 respondents were to received the questionnaires, a rate of returned of 50 respondents was to be expected. This number may constitute too small a sample since the objective of the research was to discover the number of respondents who have applied VM to their projects, which could be a small percentage of the total respondents.

Due to the reasons stated above, it was decided that all of the potential respondents were to receive the questionnaire. The exception was the registered engineers, due to economic reasons; only $20 \%$ (1582 numbers) of them were to receive the questionnaire due to their total population being 7,919 numbers of engineers. The $20 \%$ percentage was decided based on it matching with the other categories of respondents, which 1353 number of registered developers, 1675 number of registered architects, 878 number of registered quantity surveyors and 93 number of registered project management companies with the Ministry of Finance.

Thus, in order to ensure its construct validity, 5581 numbers of questionnaires were mailed to all the registered developers and registered consultants of the Malaysia construction industry. This was an extremely wide coverage of potential respondents involved with the Malaysia construction industry.

\subsection{Research Methodology}

According to Emory \& Cooper (1991), in order to obtain the research objectives stated, research design is used to plan the overall programme and structure of the problem under investigation, thus empirical evidence can be discovered. Thus, the choice of research methodology employed depends on the nature, features and context of the research. This research aimed to investigate the current development of VM and to discover the level of VM applications in the construction projects in Malaysia. Therefore, it involved discussion on factors related to the construction industry in order to be able to give a holistic view of its impact on the local construction industry.

\subsection{Research Design}

The need for research design stems from a skeptical approach to research and a view that scientific knowledge must always be provisional. Its purposed is to reduce the ambiguity of much research evidence. It is contended by Yin (1989) that research design deals with a logical problem and not a logistical problem and Fellows \& Liu (2003) added that research methods and styles are not usually mutually exclusive, although only one, or a small number of approaches, will normally be adopted due to resource constraints on the work. The different approaches focus on collection of data rather than examination of theory and literature. The methods of collecting data impact upon the analyses which may be executed and, hence the results, conclusions, values and validity of the study (Fellows \& Liu, 2003).

The decision to use the questionnaire method in the study was mainly because the nature of the Malaysia construction 
industry which covers the overall geographical area of Malaysia, thus techniques such as snow balling were not appropriate due to this study being exploratory in nature. After an extensive literature review search on the area, there was no such study which had been conducted in the local context. The questionnaire survey methods also made it possible to contact more subjects in a limited time in comparison with other methods, such as interviews, would have permitted.

\section{Data Analysis}

The data analysis process was conducted by using SPSS version 12 and several types of statistical analysis were applied such as frequency analysis, cross-tabulation, Chi-square test of association, Levene's test and one-way ANOVA. Table 1 presents the summary of results of data analysis conducted in the study.

As for the questionnaire, it was designed to tap the demographic information on education level, job title, and organization background of the respondents as well as their years of experience in the local construction industry. The survey also asked the related questions on the details of the VM application as well as the suggestion for future implementation of VM.

\subsection{Assessing the Internal Consistency of the Instrument}

There were two sections in the questionnaire (instrument) which required respondents to respond to each item based on a 5 -Likert scale response format $(1=$ Strongly agree to $5=$ Strongly disagree). The sections were perceptions of the constraining factors for applying VM and suggestions to ensure better implementation of VM in the Malaysian construction industry. Each section had five variables involved, namely the perception of public level, higher institutions, implementation purposes, client's level and consultant's level.

To ensure the reliability or the accuracy in measurement of the questionnaire, which indicated that it was consistently measured and helped to assess the goodness of a measure, the interitem consistency reliability method was employed to test the consistency of respondents' answer to all the items measured (Sekaran, 2003). Therefore, Cronbach's Alpha coefficient $(\alpha)$ was used to measure the internal consistency of the instrument. Alpha's coefficient ranged in value from 0 to 1 . It was used to describe the reliability of the instrument for multi-point formatted scales (i.e., $1=$ very dissatisfied to $5=$ very satisfied). The higher the value, the more reliable the instrument was. Firstly, the consistency of respondents' answers to all items was assessed. The coefficient of 0.9113 which indicated that the internal consistency for the entire scale was good as it was above 0.7 . Then, the internal consistency for each variable in both sections was assessed and the results are summarised in Table 2 and Table 3 respectively.

The Alpha coefficient for all constraining factor variables ranged from 0.7234 to 0.8181 hence indicated that all the variables were highly reliable and consistent. For suggestion variables, the coefficients ranged from 0.7998 and 0.8708 except for the client's level which was 0.6910 . Thus, it was excluded for further analysis since it had a poor reliability.

\section{Findings of the research}

The Survey succeeded in gathering the information and details on the current practice of VM in the Malaysian construction industry from both sectors of the industry which were the clients as well as the registered consultants. By sending the questionnaire to the registered consultants, a perspective of the Malaysian construction industry was able to be gathered from the practitioners who practiced in the both sides of the public and private sectors of the construction industry. Thus, the findings provided a holistic view of the VM application and experience was gained from the outcome of the survey.

It was concluded that the quality of the respondents of the survey was very high, due to them being highly educated and experienced as well as they had high powers of authority in decision making processes in their organisations as well as their experience which was more holistic due to their considerable experience and knowledge.

The analysis confirmed that the longer duration of their involvement in the construction industry, the higher the chance that they came across the term VM. This indicated that the awareness of VM was already established in the industry as $78 \%$ knew what VM is but only $16 \%$ of the respondents understood the VM term very well based on the training and exposure they had received. It was also found that the knowledge of the job plan had also no significant association with the type of organisation and the respondent's working experience in the construction industry.

It was also discovered that the most common source of VM knowledge was from the books/journals/articles, personal experience, seminars/courses, VM seminar/talk (74), university (67), VM workshop (41) and lastly VM training course (31). This indicated that promotion of VM should be more aggressive especially in producing publications, seminars and training course in VM.

The number of respondents who had formal training on VM still can be considered very low as it was only $14.0 \%$ and most of them had completed an Introductory Course to VM rather than completed the Module 2 of VM training. Despite the low percentage on the formal training, it was encouraging to discover that the majority of the respondents (75\%) knew the VM methodology irrespective of types of organisation the respondents represented and their working 
experience in the construction industry.

The main reason why VM was applied in the first place, was due to the client being able to achieve value for money, followed by it is a useful and efficient method to reduce unnecessary costs as well as it is a value enhancing tool. This is an interesting point to note that it was confirmed by $99 \%$ of the respondents who agreed that VM was applicable to the Malaysian construction industry. This indicated that the respondents strongly felt that the current construction industry needed the input from the VM concept and it is very relevant to the Malaysia construction industry.

The result also confirmed that the majority $(51 \%)$ of the respondents did not practice the VM methodology in their working environment and a large number of organisations had no experience in any workshop in the application of VM study in the construction projects procured despite that $99 \%$ of the total respondents agreed that VM is applicable to the local construction industry. Seventy five per cent $(75 \%)$ of the respondents confirmed on the matters pertaining to the job plan as they agreed with the stages of the job plan listed on the questionnaire and they recognised it as stages involved in the VM study.

Among the criteria which indicated the practice of VM in the current scenario of the Malaysia construction industry, the majority of the projects which had applied the VM methodology were in the region of RM11m and RM50m of project value. It was also found that more than half of the projects (57\%) used in-house facilitators to facilitate the VM workshops rather than hiring an independent VM facilitator. The types of formal VM approaches used were mainly the concurrent study and 2-3 days of VM workshops.

Based on the analysis conducted, the majority of the construction projects in Malaysia which had applied VM workshops which were attended by less than 10 participants, during the process of less than 3 days. They were conducted within their work environment and dominated by the clients and the consultants of the project. Most of the projects applied the VM methodology during the outline proposals stage followed by during the briefing concept of a project and $64 \%$ had not used the FAST diagram during the process of VM.

It is also encouraging to note that $18 \%$ of the respondents were extremely satisfied and $60 \%$ of them were satisfied concerning the output of the VM studies. Fifty two per cent (52\%) of $149 \mathrm{VM}$ projects recorded the saving of the initial cost of projects of up to $10 \%$, while $25 \%$ stated they managed to saved up to $30 \%$ of the initial cost of projects after VM workshops implementation.

Among the highest reasons detected on why the processes of VM were applied to the respondents' construction projects were to ensure better value for money as well as to eliminate the unnecessary costs; to seek alternatives as well as to review the existing design and to ensure that clearer focus on project's objectives and to enhance better value. The respondents also stated that the application of VM in their projects was due to the purpose that they wanted to fulfill the clients' requirement and to encourage creativity. Only 18 respondents stated that one of the reasons why VM methodology was carried out in their construction projects was because to pursue management fashion.

It is also important to note that the most important benefits gained from the VM applications, according to the respondents, were that VM was able to eliminate unnecessary costs, it produced a better value in a project, lowered construction cost, the clients' requirements were better met, as well as the project outcome produced a better functionality. All these elements produced a more satisfied client and the respondents realised that the VM process improved the decision making process as well as better team working was produced as a result of the process. These were among the important criteria that the respondents stated they gained from the VM process.

It is confirmed that lack of VM knowledge and practice were the main problems faced during the VM workshop; the resistance to change by the involved parties during the VM workshops sessions as well as the conflicting objectives of the project by different parties. It was also discovered that many related parties involved in the exercise tended to have negative mindsets towards the VM process which resulted in poor team working. Another contributing factor to the problem faced was due to lack of input from the related specialists' as well as poor facilitation skills during the VM workshops.

\section{Conclusions}

The development of VM in the Malaysian construction industry should be continuously research and monitored in the future in order to ensure its further development and for the construction industry to benefit further as the industry moves from the developing country stage. Based on the findings, further research on VM is required to ensure further insight and evidence on why and how VM methodology was applied, whether there was a need and room for the VM applications in the future of the Malaysia construction industry. Due to the positive outcome of the research in the area of VM application in the current situation of the Malaysian construction industry, it is hoped that the details of VM practice could be probed further by conducting interviews to the selected respondents who have applied VM. By doing so, comprehensive details can be obtained to confirm its practice was as according the VM methodology.

It was concluded that there was an encouraging result towards the future of VM in the Malaysia construction industry 
when more than $80 \%$ of the respondents from various segments of the industry stated they were interested to integrate the VM application in their future projects. The analysis also revealed that the project manager was voted to be the best person to be a VM facilitator in Malaysia followed closely by the quantity surveyor. It was also discovered that the majority of the respondents wanted VM as the tool to reduce the cost. Beside that, many respondents also needed a VM so as to clarify the need for a project as well as to review the design and to develop a better project brief. They also require VM in order to ensure that they could have better involvement in the projects.

\section{References}

Abdul Ghani, M. A. (2004). Value Management (VM) Practice in Malaysia: The Principles and Method. Unpublished MBA, International Islamic University Malaysia, Kuala Lumpur.

Ashworth, A., \& Hogg, K. (2000). Added Value in Design and Construction. Essex: Pearson Education Limited.

BERNAMA. (2002). KLIA Benefits from Value Management. New Straits Time,

Che Mat, M. M. (1999). Value Management: Towards Achieving Better Value for Your Money. Johor: Professional Centre for Value Management Sdn Bhd.

Che Mat, M. M. (2002). Value Management: Principles and Applications. Petaling Jaya: Prentice Hall.

Connaughton, J. N., \& Green, S. D. (1996). Value Management in Construction: A Client's Guide. London: Construction Industry Research and Information.

de Vaus, D. (2001). Research Design in Social Research. London: SAGE.

Ellis, R. C. T., Wood, D. G., \& Keel, D. A. (2005). Value Management practices of leading UK cost consultants. Construction Management and Economics, 23, p. 483-493.

Emory, C. W., \& Cooper, D. R. (1991). Business Research Methods: Irwin, Homewood.

Fellows, R., \& Liu, A. (2003). Research Methods for Construction (2nd Edition ed.). Oxford: Blackwell Science.

Green, S. D. (1999). A participative research for propagating soft methodologies in value management practice. Construction Management and Economics, 17(3), pp. 329-341.

Hussein, J. (1998, 23th March 1998). Value engineering in the KL International Airport Project. Paper presented at the Cabaran Kejuruteraan Nilai dalam Industri Pembinaan, UTM, Kuala Lumpur.

Jaapar, A. (2000). The Case for Value Management to be included in every Construction Project Design Process. Unpublished MSc. Dissertation, Universiti Teknologi MARA, Shah Alam.

Jaapar, A. (2006). The Application of Value Management in the Malaysian Construction Industry and Development of Prototype Value Management Guidelines. Universiti Teknologi MARA, Shah Alam, Selangor.

Jaapar, A., \& Torrance, J. V. (2005). Value Management and its Current Status in Malaysia. The Malaysian Surveyor, 39.2(February), pp. 14-25.

Jaapar, A., \& Torrance, J. V. (2007). Prototype Value Management Guidelines for the Malaysian Construction Industry. Paper presented at the QSIC 2007- Enhancing \& Empowering the Profession, Crown Plaza Mutiara Hotel, Kuala Lumpur, Malaysia.

Jaapar, A., Torrance, J. V., \& Yusuf, F. (2004). Preliminary Survey of Client Satisfaction \& VM Application in the Malaysian Construction. Paper presented at the MiCRA 3rd Annual Conference, Langkawi.

Karim, S. B. A. (1999). Value Management in the Malaysian Construction Industry: Application during Design Stage. Unpublished BSc. Dissertation, Universiti Malaya, Kuala Lumpur.

Kelly, J. R., \& Male, S. (1991). The practice of Value Management: Enhancing Value or Cutting Cost? London: The Royal Institution of Chartered Surveyors.

Kelly, J. R., \& Male, S. (1993). Value Management in Design and Construction: The Economic Management of Projects. London: E \& FN Spon.

Kelly, J. R., Male, S., \& Graham, D. (2004). Value Management of Construction Projects.Unpublished manuscript, London.

Liu, G. (2003). A Framework For Implementing Value Management in China's Construction Industry. Unpublished PhD, The Hong Kong Polytechnic University, Hong Kong.

Male, S., Kelly, J. R., Fernie, S., Gronqvist, M., \& Bowles, G. (1998). The Value Management Benchmark: Research Results of an International Benchmarking Study. London: Thomas Telford.

Norton, B., \& McElligott, W. C. (1995). Value Management in Construction: A Practical Guide. London: McMillan Press. 
Ong, H. T. (2004a). Quality and value management in construction. Paper presented at the International Conference on Managing Excellence in Construction, Chongqing, China.

Ong, H. T. (2004b). Value-Managed Quality System: Towards A Value-Added Quality Management System. Master Builders, 1 st Quarter, p. 54 - 63.

Ong, H. T., \& Yeomans, P. R. (2002). Value management: enhancing project cost performance. Berita QS, March, pp. $2-6$.

Sareh, M. A. (2003). Value Management: The Implementation for Government Funded Projects. Unpublished BSc. Dissertation, Universiti Teknologi MARA.

Sekaran, U. (2003). Research Methods for Business: A Skill Building Approach (4th Edition ed.). New York: John Wiley \& Sons.

Shamsuddin, M. (2002). The Implementation of Value Management in the Public Sector. Unpublished MSc., Universiti Teknologi MARA, Shah Alam, Selangor.

Shen, Q. (1995, August 1995). A knowledge-based model for coordinating design through value management. Paper presented at the Modelling of Buildings Through Their Life-cycle, Stanford.

Stevens, D. (1997). Strategic Thinking: Success Secrets of Big Business Projects. Sydney: McGraw-Hill.

Sulaiman, M. S. (2000). Value Management in Malaysian Construction Industry: Study in Construction Phase. Unpublished Bachelor Dissertation, Universiti Malaya, Kuala Lumpur.

Tamim, R. (2002). Reasons for Successful Value Management Study in Malaysian Construction Industry. Unpublished BSc. Dissertation, Universiti Teknologi MARA, Shah Alam.

WCGPM (2004). Wideman Comparative Glossary of Project Management, Definition. Journal. Retrieved from http://www.maxwideman.com/pmgglossary/

Yahya, I. A. (2003). Value Management as an Aid to Communication During Design Stage in Klang Valley Construction Industry. Unpublished MSc., University of Malaya, Kuala Lumpur.

Yin, R. K. (1989). Case study research: Design and methods (Revised Edition): London, SAGE. 


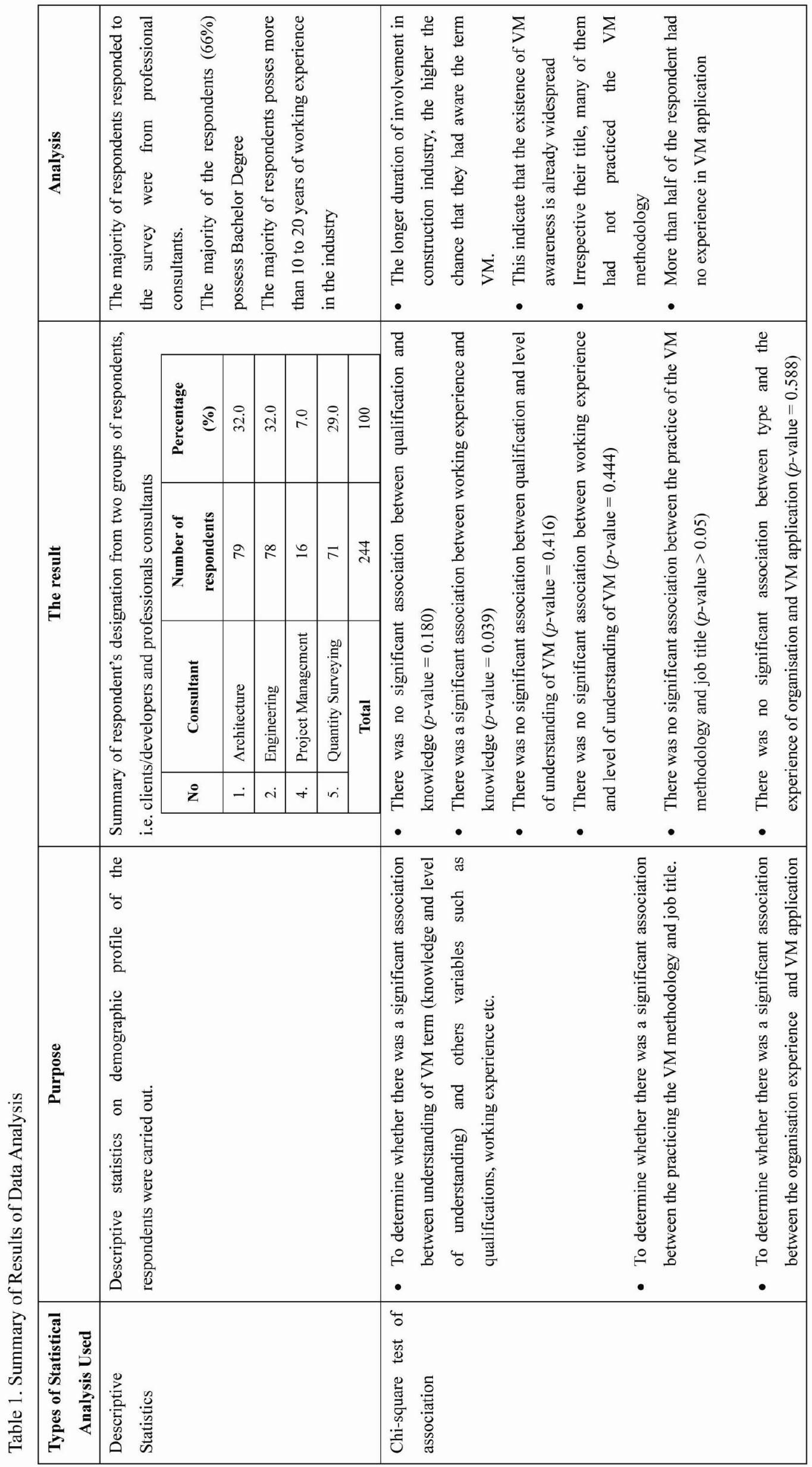


Table 1 continue

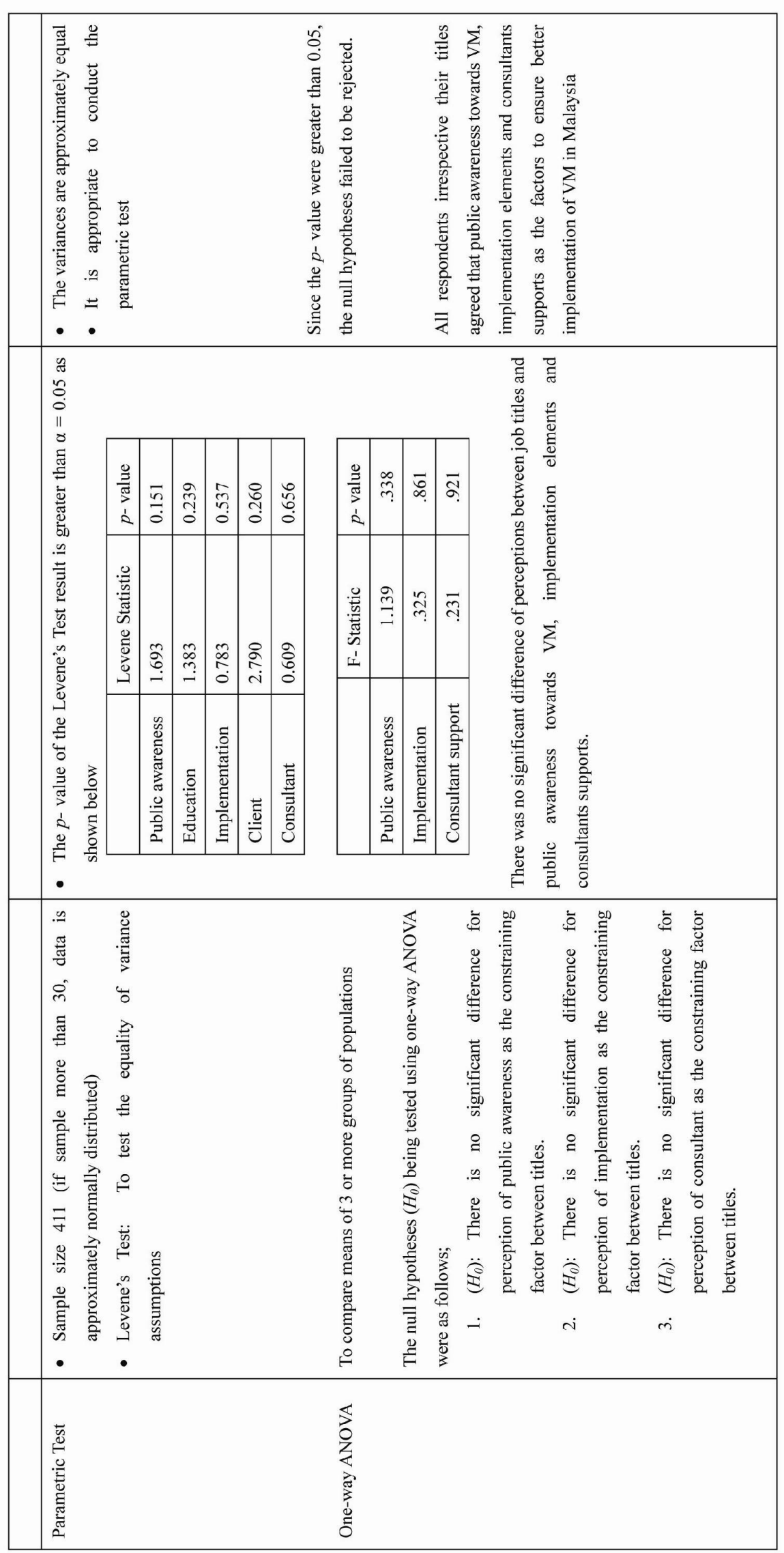


Table 2. Summary of Result of the Reliability Test (Constraining Factors)

\begin{tabular}{|c|c|c|}
\hline Variables & No. of items & Alpha coefficient \\
\hline Public level & 3 & 0.7234 \\
\hline Higher institutions & 2 & 0.8027 \\
\hline Implementation purposes & 5 & 0.7667 \\
\hline Client's level & 6 & 0.7774 \\
\hline Consultant's level & 8 & 0.8181 \\
\hline
\end{tabular}

Table 3. Summary of Result of the Reliability Test (Suggestions)

\begin{tabular}{|c|c|c|}
\hline Variables & No. of items & Alpha coefficient \\
\hline Public level & 3 & 0.8708 \\
\hline Implementation purposes & 6 & 0.8553 \\
\hline Client's level & 2 & 0.6910 \\
\hline Consultant's level & 3 & 0.7998 \\
\hline
\end{tabular}

